\title{
E्दुreatidaro
}

\section{Biopolítica e Educação: relações a partir das discursividades sobre saúde na escola}

João Paulo Pereira Barros

RESUMO - Biopolítica e Educação: relações a partir das discursividades sobre saúde na escola. $\mathrm{O}$ artigo discute relações entre biopolítica e educação a partir dos agenciamentos produzidos pelas práticas discursivas sobre saúde no contexto escolar. O texto toma por base: 1) a consulta à literatura que, remetendo-se à história da educação brasileira, trata da inserção das práticas de saúde no âmbito escolar; 2) resultados de uma pesquisa de mestrado que buscou compreender a mediação das interações de um grupo de discussão sobre saúde, em uma escola de Fortaleza, nos posicionamentos dos participantes frente aos temas discutidos. Assim, discute-se como os agenciamentos produzidos por práticas de saúde na escola evidenciam a aliança entre mecanismos disciplinares e biopolíticos que visam regular a vida dos segmentos infantojuvenis.

Palavras-chave: Biopolítica. Educação. Saúde. Produção de Subjetividade.

ABSTRACT - Biopolitics and Education: relations from discursitiy about health at school. This paper aims to discuss the relations between biopolicits and education from the agency theories produced by the discursive practices about health on the scolhar context. The paper is based on: 1) literature consulting that, refering to the history of brazilian education, shows the insertion of the practices of health at school; 2) results from a master's degree research that intented to understand the mediation of the interaction of a discussion grouo about health, at a school from Fortaleza, on the participant's postion about the chosen subjetcs. Thus, it is discussed how the agency theories produced by practices of health at the school evidence the link between disciplinary and biopolitical mechanism that aim to regulate the life of juvenile sections.

Keywords: Biopolitics. Education. Health. Subjectivity Production.

Educação \& Realidade, Porto Alegre, v. 38, n. 1, p. 361-381, jan./mar. 2013.

Disponível em: <http://www.ufrgs.br/edu_realidade> 


\section{Introdução}

As tecnologias políticas que exerciam controle sobre os corpos e que condicionavam o funcionamento das sociedades ocidentais modernas - bem como de suas instituições, dentre elas a escola - transformaram-se significativamente no século XVIII, segundo Foucault (1999). A partir de então, passou-se a estar às voltas com uma modalidade nova de poder, que, diferentemente das anteriores, encarregava-se da vida, e não da morte: o biopoder.

Para Foucault (1999, p. 302), o biopoder é aquele que "se incumbiu da vida em geral, com o polo do corpo e o polo da população”. Para o autor, o poder disciplinar e a biopolítica incidem, respectiva e articuladamente, sobre o indivíduo e sobre a coletividade. O poder disciplinar se baseia no panóptico e age no corpo-organismo, no indivíduo, a fim de discipliná-lo. Já a biopolítica atua num outro tipo de corpo, o corpoespécie, tendo como objeto os modos de vida da população e estabelecendo mecanismos de regulação social.

Desse modo, Foucault (1999) aponta um dos fenômenos fundamentais do século XIX: o aparecimento de uma nova tecnologia de poder caracterizada por fazer viver e deixar morrer, diferentemente do poder soberano, que se alicerçava no direito de matar e se exercia a partir de mecanismos de castigo e tortura.

Gadelha (2009) ressalta que, antes de Foucault, as problemáticas relativas à biopolítica vinham sendo tratadas sob uma perspectiva jurídico-política ou jurídico-filosófica do poder. Foi Foucault quem, de maneira efetiva, abordou o assunto sob um viés histórico-político ou histórico-filosófico, imanentista e microfísico do poder. Nesta perspectiva, o poder é compreendido como relacional, estratégico, acentrado, exercendo-se de formas diversas, em diferentes níveis sociais, e não como uma propriedade identificada necessariamente com o Estado e deduzida da economia. Assim, para Foucault (1979), o poder não só coage, reprime e proíbe, mas também é constitutivo, participando ativamente da produção de subjetividades por exemplo.

Foucault começou a desenvolver sua discussão sobre biopolítica em 1974, frisando como a medicina social se configurou como uma estratégia de regulação da vida da população no século XIX. Naquele contexto, segundo Foucault (1979), a biopolítica vinculava-se historicamente à constituição e ao fortalecimento do Estado nacional, bem como à afirmação da burguesia e à formação de um dispositivo médico e jurídico ligado à normalização social.

Entre 1977 e 1979, o autor formula suas últimas discussões sobre biopolítica, em dois cursos ministrados no Collège de France: segurança, território, população (Foucault, 2008a) e Nascimento da Biopolítica (Foucault, 2008b). Esses cursos dão novos e mais complexos contornos à discussão: em ambos, é abordada a questão da governamentalidade, 
sendo que, no segundo curso, o autor aborda o liberalismo e o neoliberalismo como refinamentos da arte de governar. Segundo Foucault (2008a, p. 49, grifo nosso), a governamentalidade diz respeito a uma sequência de operações estabelecidas no "contato entre as tecnologias de dominação dos outros e as voltadas para o $e u$ ”, atuando, portanto, simultaneamente, na regulação das condições de vida da população e da existência dos indivíduos. Tais questões são de suma pertinência para o campo da educação, especialmente por suscitar questionamentos sobre seu papel na contemporaneidade.

Mas, afinal, qual a relação entre biopolítica e educação? Segundo Gadelha (2009, p. 15), os nexos entre uma e outra não são um fato óbvio e devidamente assinalado na obra de Foucault, mas sim algo a ser traçado a partir dela:

De fato, objetivamente falando, ele [Foucault] não tomou a educação - como o fez, por exemplo, com a medicina social (a medicalização da vida, a instalação de um dispositivo da sexualidade), a polícia, a previdência social e o racismo biológico de Estado, dentre outros - como um dos mecanismos estratégicos privilegiados para o exercício de biopoderes e de biopolíticas nas sociedades ocidentais modernas.

Partindo desse ponto, e dialogando inventivamente não só com Foucault, mas também com outros interlocutores que nele buscam inspiração, a proposta deste artigo é discutir pistas de possíveis relações entre biopolítica, educação e produção de subjetividade no cotidiano escolar. Considero, aqui, o pressuposto de que a escola é uma importante agência de produção de territórios existenciais. Pressuponho, ainda, que, em diversas situações do cotidiano escolar, o signo saúde vem se configurando cada vez mais como um equipamento de enunciação coletiva (Guattari; Rolnik, 2005), a se somar à polifonia de vetores de subjetivação juvenil-adolescente que atravessam as relações escolares.

Assim, neste trabalho, interessa-me a questão: como os agenciamentos produzidos pelo signo saúde no contexto escolar indicam a presença de mecanismos biopolíticos no campo educacional?

Para isso, tomo por base: 1) o diálogo com autores que, remetendose à história da educação brasileira, tratam da inserção das práticas de saúde particularmente no âmbito escolar; 2) resultados de uma pesquisa de mestrado em psicologia, concluída em 2010, a qual buscou compreender a mediação das interações de um grupo de discussão sobre saúde, realizado com adolescentes em uma escola pública de Fortaleza, nos posicionamentos dos participantes frente aos temas discutidos.

A título de esclarecimentos, a referida dissertação consistiu numa pesquisa-intervenção cuja etapa empírica foi executada de agosto a novembro de 2009. Naquele período, foram realizadas observações-participantes do cotidiano de uma escola pública de ensino fundamental 
e médio de Fortaleza. Os critérios elaborados para auxiliar a escolha da escola foram de que a instituição (a) desenvolvesse trabalhos com jovens à época da realização da pesquisa; (b) discutisse questões relacionadas à saúde ou tivesse interesse em fazê-lo com jovens; (c) demonstrasse disponibilidade e interesse de ser o local de realização da investigação.

Além disso, na escola-lócus, foi formado, por ocasião da pesquisaintervenção, um grupo de discussão sobre saúde, o qual contou com onze participantes - dez jovens estudantes de 15 a 17 anos, sendo 3 do sexo masculino e 7 do sexo feminino, e um professor. Quanto ao número de componentes, o ponto de partida assumido foi de que, num grupo de 10 a 15 pessoas, tanto a dinâmica de interlocução entre os partícipes seria mais efetiva, quanto o uso de técnicas para facilitar as interações se tornaria mais eficiente, além de que se teriam condições de viabilizar a intervenção mesmo com possíveis flutuações na frequência ou por eventuais desistências.

A princípio, a proposta era que o grupo fosse formado apenas por estudantes. Mas, ao longo da entrada em campo e após interlocuções com a banca examinadora da pesquisa, durante o exame de qualificação, uma questão veio à tona: se o grupo se realizaria na escola e poderia estimular a circulação de novos sentidos sobre saúde naquela instituição, por que não contar com a participação de outros atores escolares além dos estudantes?

Assim, como critério para a composição do grupo, foi considerado que seria interessante que os participantes, jovens estudantes da escola ou profissionais da instituição, fossem pessoas que: (1) se interessassem em discutir processos de saúde/doença no cotidiano em que vivem e (2) tivessem disponibilidade de participar de todo o processo.

Em razão de tais critérios, foi estendido o convite à participação no grupo também aos profissionais da escola, e um professor se disponibilizou a participar. Isso trouxe consigo algumas incertezas: ao fazer essa opção, se assumiu o risco de que a presença de um professor nos encontros, por si só, seria capaz de mudar sua configuração, dada sua posição social diferencial em relação aos alunos. Mas, por outro lado, poderia proporcionar mais diversidade de sentidos e possibilidades de negociação de posicionamentos no grupo, o que, para a intervenção, seria um ponto positivo.

O grupo de discussão se realizou por meio de 9 oficinas sobre os seguintes temas, escolhidos pelos participantes: o que é saúde, saúde mental, transtornos alimentares, drogas e sexualidade. Vale ressaltar também que as interações dos participantes durante as oficinas foram videogravadas e, em seguida, transcritas, a fim de proporcionar melhores condições para a análise dos processos de negociação de posicionamentos sobre os temas. Tais procedimentos foram devidamente autorizados tanto pelos responsáveis legais pelos adolescentes, quanto pelo 
Comitê de Ética em Pesquisa da Universidade à qual a pesquisa esteve vinculada.

Cada oficina transcorreu em torno de uma hora e meia. Em todas as oficinas, foi realizado um momento de acolhida, em geral a partir de músicas, servindo como um quebra-gelo no início de cada encontro. Após essa acolhida, eram realizadas atividades que servissem, sobretudo, como uma sensibilização para a temática da oficina, fosse trazendo uma letra de música a ser analisada, sugerindo dramatizações ou colagens sobre a temática, trazendo notícias de jornal, fosse sugerindo alguma outra técnica de trabalho grupal. Em seguida, adentrava-se na discussão do tema a ser especificamente trabalhado, geralmente a partir de questões suscitadas pelo momento de sensibilização. Por fim, era realizada uma avaliação do encontro, mediante a qual se reiterava a data do encontro seguinte e sua respectiva temática a ser discutida.

Apesar de todas as oficinas seguirem esse percurso, as definições de quais recursos utilizar em cada oficina foram acontecendo a partir da inserção na dinâmica da escola e no curso da intervenção. Desse modo, cada encontro funcionou "como orientador do modus operandi do próximo” (Menezes; Arcoverde; Libardi, 2008, p. 205).

\section{Práticas de Saúde na Educação Brasileira: um panorama histórico}

Para entender a inscrição da discursividade sobre saúde na escola e como os atores escolares operaram com esses discursos, é necessário, a princípio, realçar propósitos e concepções ligadas à própria construção da escola que temos atualmente. Afinal, como lembra Foucault (1996, p. 12), a produção do discurso em toda sociedade "é controlada, selecionada, organizada e redistribuída por um certo número de procedimentos que têm por papel exorcizar-lhe os poderes e os perigos, refrear-lhe o acontecimento aleatório, disfarçar a sua pesada, temível materialidade".

Nossas escolas remetem historicamente à Idade Moderna, quando as concepções sociais acerca da infância sofreram modificações significativas e o Estado passou a ter um maior interesse na formação das crianças. De lá para cá, a escola vem exercendo um papel essencial na construção do sujeito moderno (Veiga-Neto, 2000). Foucault (2005), por exemplo, é enfático ao afirmar que ela faz parte de um conjunto de instituições que serviriam não apenas como local de transmissão e acúmulo de saber, mas como arregimentadoras de um campo de experiência para os que nela se inserem, atuando no delineamento da relação do indivíduo com os outros e consigo.

Esses apontamentos a respeito do surgimento da escola na Modernidade convergem com as elaborações de Foucault sobre as relações de poder. Em Vigiar e Punir, Foucault (2005) assinala que, entre o século 
XVIII e o século XIX, uma nova tecnologia de poder organizada em torno da disciplina começava a ganhar relevo. Foucault (2005, p. 127) faz referência a um esquadrinhamento disciplinar da sociedade e a uma política de coerções que "são um trabalho sobre o corpo, uma manipulação calculada de seus elementos, de seus gestos, de seus comportamentos. O corpo humano entra numa maquinaria que o esquadrinha, o desarticula e o recompõe”. Notadamente, esses processos se presentificavam de forma marcante no funcionamento da escola moderna, sendo ainda bastante arraigado atualmente em diversos contextos escolares.

A construção social, no século XX, da categoria juventude, como período de transição da infância para a idade adulta, deu à escola uma importância ainda maior. Os primeiros estudos no campo da psicologia do desenvolvimento sustentavam que essa transição associava-se a crises manifestadas das mais diversas formas - contradições, confusões, ambivalências, rebeldia, impulsividade, imaturidade e fricções não só com o ambiente circundante (Aberastury, 1980). Dessa forma, autores como Abramo (2008, p. 41) apontam de que forma a escola vem se inserindo entre as principais instituições cuja função é de fazer com que tal transição se dê com êxito:

[...] a juventude 'nasce' na sociedade moderna ocidental (tomando um maior desenvolvimento no século XX), como um espaço a mais de preparação (uma segunda socialização) para a complexidade das tarefas de produção e sofisticação das relações sociais que a sociedade industrial trouxe. Preparação feita em instituições especializadas (a escola), implicando a suspensão do mundo produtivo (e da permissão de reprodução e participação); estas duas situações (ficar livre das obrigações do trabalho e dedicado ao estudo numa instituição escolar) se tornaram os elementos centrais de tal condição juvenil.

Ora, de que maneira o entendimento sobre a própria constituição da escola ajuda a entender nuances das práticas de saúde no espaço escolar? Conforme Stephanou (1996), as práticas de saúde na escola se iniciaram no Brasil no começo do século XX, sob uma vertente higienista, como ferramenta de disciplinarização dos indivíduos e como forma de controle da população. Algumas questões do início daquele século favoreceram isso, pois acarretaram crises na área da saúde:

$$
\begin{aligned}
& \text { A varíola - uma doença atualmente erradicada em todo o } \\
& \text { mundo - era um grande problema para a saúde pública e } \\
& \text { epidemias de cólera e peste bubônica comprometiam as } \\
& \text { atividades de comércio exterior do país. A isso se somava } \\
& \text { uma epidemia de febre amarela urbana e a alta incidên- } \\
& \text { cia de doenças ainda hoje comuns à realidade brasileira } \\
& \text { tais como malária, sífilis, tuberculose e hanseníase. Tal } \\
& \text { quadro nosológico tinha como tradução uma alta morta- } \\
& \text { lidade da população em geral, obviamente agravada nas }
\end{aligned}
$$


crianças, vitimizadas também pela desnutrição, por diarréias ou por doenças hoje imunopreveníveis tais como sarampo, tétano, coqueluche e difteria (Figueiredo et al., 2010, p. 399).

Tal como argumenta Figueiredo et al. (2010), a escola, naquele contexto, constituía-se num dos lugares mais propícios para infundir uma consciência sanitária na população. Um dos motivos para isso radicava-se no fato de a escola ser ocupada principalmente por crianças, adolescentes e jovens, segmentos vistos como ainda em amadurecimento para a vida adulta e que deveriam ser foco de uma atenção maior das práticas de saúde, a fim de que se garantisse um gerenciamento das crises que supostamente marcavam o amadurecimento desses atores.

De acordo com a avaliação de Lima (1985, p. 85), a inserção da saúde na escola - a princípio, também conhecida como higiene escolar - ocorreu pelo entrelaçamento de três doutrinas: a polícia médica, "pela inspetoria das condições de saúde dos envolvidos com o ensino"; o sanitarismo, "dada à prescrição a respeito da salubridade dos locais de ensino" e a puericultura, em função da "difusão de regras de viver para professores e alunos".

Aqui surge uma questão: quando as práticas relacionadas à saúde foram introduzidas na escola, que sentidos faziam circular e o que produziam no que diz respeito à constituição subjetiva dos atores escolares? Segundo Stephanou (1996, p. 65), aquelas práticas constituíam formas sutis de cruzar mecanismos de disciplinamento, de docilização e de regulação biopolítica, pois sua conclusão principal, ao estudar tal inserção no início do século, foi de que

\begin{abstract}
[...] a escola, além de proporcionar o aprendizado das interdições, das proibições, das punições, estabeleceu práticas em que as crianças e os jovens, entre si, e de si para consigo, além de se ocuparem do exercício de um autocontrole, estiveram envolvidos em procedimentos complexos, definidores de um novo cuidado de 'si para si'. Tais preocupações evidenciam um intricado mecanismo de internalização de tecnologias de poder individualizantes. Que cuidado? Aquele intimamente associado à prática de saúde, à higiene do corpo e asseio das roupas, aos modos de proceder, à pureza da alma, à nobreza do caráter. Cuidado igualmente com a obtenção e preservação da saúde física e moral.
\end{abstract}

Além disso, a individualização dos condicionantes dos processos de saúde/doença também era característica das atuações tradicionais nesse âmbito. Nesse primeiro momento, para Schall e Struchiner (1999, p. 4), uma dimensão era privilegiada por essas práticas, sendo que ela persiste até hoje: tratava-se da "aprendizagem sobre as doenças, como evitá-las, seus efeitos sobre a saúde e como restabelecê-la”. Já conforme a crítica de Figueiredo (2010, p. 400), a escola, na maioria dos casos, era 
vista como lugar de controle e prevenção de doenças, comumente representada pelas instituições de saúde como um grupo passivo para a realização de suas ações:

\begin{abstract}
Usualmente os técnicos da área de saúde têm compreendido a educação em saúde na escola como intervenções pontuais, a respeito de conteúdos afeitos a questões nosológicas do momento. Técnicos de saúde falam, por exemplo, de dengue na escola para crianças e adolescentes porque uma epidemia de dengue assola a sociedade. Trata-se, a nosso ver, de uma intervenção, no mínimo, equivocada visto que, conforme preconizam os parâmetros curriculares nacionais - PCN -, os conteúdos de saúde devem comparecer no currículo da formação de crianças e adolescentes como uma abordagem transversal e interdisciplinar.
\end{abstract}

No século XX, como marco legal da cristalização da saúde nas escolas, tem-se a criação da Lei de Diretrizes e Bases da Educação Nacional - LDB-9394/96 (Brasil, 1996), a partir da qual novas regulamentações passaram a reger a educação brasileira. A fim de garantir uma base comum ao ensino nas regiões do país, o Ministério da Educação (MEC) elaborou os Parâmetros Curriculares Nacionais (PCNs), estabelecendo diretrizes para o currículo e servindo de referência para a prática educativa e para as ações políticas na seara educacional.

De acordo com os PCNs, alguns conteúdos devem ser organizados em temas transversais, a serem trabalhados em cada área do conhecimento. Assim, questões como saúde e orientação sexual se incluem entre esses temas transversais apontados pelos PCNs (Brasil, 1997). Logo, a proposta do MEC esboça a saúde como uma das peças-chave para a articulação entre as diferentes atividades e disciplinas escolares, bem como entre estas e a sociedade.

Como desdobramento prático da consolidação da saúde como um tema-chave, no final do século XX, o que se percebe, em determinados cotidianos escolares, é a intensificação da entrada de diversas categorias profissionais de saúde para falar sobre assuntos diversos na escola, como médicos, enfermeiros, psicólogos. Nesse contexto, o que também se percebe é que práticas e concepções disciplinarizantes e de regulação biopolítica continuam tendo lugar, sendo, inclusive, a tônica que rege as discussões sobre saúde em muitas escolas. Esse panorama, por sinal, encontra similaridades com exemplos citados por Gadelha (2009, p. 179-180) de como a educação e a escola se constituem veículos e lugares de controle do corpo-espécie da população:

Em primeiro lugar, lembremos que a pedagogia, a educação e a escola foram e ainda são frequentemente acionadas, como elementos auxiliares, complementares e às vezes até mesmo essenciais, para a viabilização de iniciativas, programas e/ou campanhas que envolvem seja 


\begin{abstract}
o esclarecimento, a prevenção e outros cuidados com a saúde das massas, particularmente, da população infantojuvenil (campanhas de vacinação, de higiene bucal, programas de nutrição infantil, de prevenção às doenças sexualmente transmissíveis, educação física, etc.) [...]. Em segundo lugar, assinalemos que, em meio a tudo isso, elas também acolhem, reproduzem e reforçam determinadas prescrições normativas, hábitos e condutas estreitamente vinculados à regulamentação e ao controle dos fenômenos inerentes à população, mas provindos de outras instituições e/ou setores sociais.
\end{abstract}

Sem perder de vista uma ontologia do presente, a fim de dar continuidade a esse panorama, convém o encerrarmos destacando, ainda que concisamente, que, além da questão da saúde nas escolas, vários outros temas fazem parte das possíveis relações entre biopolítica e educação, nos nossos dias, assim como realça Gadelha (2009), tais como: a revolução tecno-informacional, a multiplicação das relações familiares, o advento de um novo capitalismo, de caráter transnacional e financeiro, a teoria do capital humano, o empreendedorismo, dentre outros.

\title{
Nexos entre Biopolítica e Educação a partir de um Grupo de Discussão na Escola
}

Nesta seção, serão analisados episódios das interações entre jovens nas oficinas de um grupo de discussão. Tratam-se de episódios extraídos do corpus da dissertação referida alhures, para trazer mais ilustrações de como é possível estabelecer nexos entre biopolítica e educação a partir das práticas discursivas sobre saúde no contexto escolar.

Até mesmo a escolha de determinados temas das oficinas por parte dos jovens pode me oferecer pistas para o estabelecimento desses nexos. A sugestão de temas como sexualidade e drogas pelos próprios

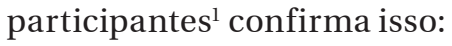

Lia: Uma coisa que é sempre bom saber é sobre as DST, doenças sexualmente transmissíveis, sempre é bom saber sobre isso, pra gente tá informado né (virada para os demais, sua entonação e sua feição são de advertência para o grupo).

Mariana: Aproveita logo e bota gravidez na adolescência.

Laura: Bota sexualidade, pronto. Sexualidade, porque engloba tudo (virase para o grupo).

Mariana: É, outro que é sempre tá informado é sobre drogas.Tem muito jovem se perdendo por aí.

Pesquisador: Mas por que vocês dizem que é "sempre bom tá informado" sobre esses assuntos?

Professor Ivan: Eu concordo com isso que ela (Mariana) falou... A juventude tem que tá precavida sobre os malefícios não só da gravidez cedo demais, das DSTs e das drogas...E a escola é pra alertar sobre isso também! Pesquisador: O que é que vocês acham? (para o grupo todo). Incluímos 
"sexualidade" e "drogas" nos temas que vamos discutir?

Camila: Pode ser.

Ronaldo: Pode ser.

Pedro: Pode ser (entoação acentuada, junto com um grande suspiro, parecendo sinal de desânimo) (Barros, 2010, p. 78).

Após os participantes terem indicado os temas sexualidade e drogas, busquei ratificar a escolha daquelas temáticas e sondar o percurso dos participantes nas discussões sobre ambas. Ao mesmo tempo em que os sugeriram, os próprios proponentes davam sinais de um certo desânimo com a inclusão dos dois temas, como se eles já fossem trabalhados à exaustão na escola. Por isso, questionei-lhes se tinham mesmo interesse em incorporá-los às oficinas:

Pesquisador: Vocês já discutiram sobre droga e sexualidade alguma vez, na escola ou em outro canto?

Laura: Ô...

Lia: Com Certeza! (risos)

Renata: É só o que tem aqui no colégio! (risos)

Pedro: Demais até! (risos)

Laura: Os trabalhos que a gente faz aqui (na escola) ou é DST, ou é sexualidade, ou é droga!

[...]

Pesquisador: Então porque mesmo é que vocês querem discutir isso mais, sobre drogas e sexualidade. Não seria melhor discutir outras coisas?

Laura: Pra saber!

Lia: Porque é sempre bom saber!

Renata: Porque a cada dia que passa é uma nova descoberta, é uma nova coisa que aparece e já faz tempo que a gente não discute.

Professor Ivan: É sempre uma preocupação nossa [dos professores] tá trabalhando esses temas nas aula, tá informando, tá alertando, tá orientando o caminho...Aqui e acolá também vem gente do posto de saúde fazer tipo palestra pros alunos. E o que mais vem são esses assuntos, porque eles tão muito atuais, né? Quanto mais trouxer esses temas na escola, melhor pra eles [os jovens] fazerem as escolhas mais saudáveis... se prepararem melhor pro futuro (Barros, 2010, p. 79).

Diferentemente do que ocorrera até então naquele grupo, a proposta de incluir tais temas pareceu decorrer mais de uma suposta obrigatoriedade de contemplá-los em uma discussão sobre saúde na escola, e não tanto de uma curiosidade dos participantes em cotejá-los. Desse modo, os posicionamentos dos jovens e do professor, nesse caso, assentavam-se numa mesma discursividade: a despeito de a abordagem sobre drogas e sexualidade soar até exaustiva, tais temas deveriam ser sempre uma preocupação dentro da escola, a fim de que os jovens se mantenham cada vez mais informados e alerta.

Ademais, cabe problematizar a influência da presença e do posicionamento do professor nesse processo de definição dos assuntos que seriam abordados. Tem-se, pois, uma interferência direta da presença do professor na delimitação dos temas sexualidade e drogas, sendo que 
o discurso docente, nesse caso, remete à ordem hegemônica de que a escola se constitui lócus ativo de produção e reprodução.

Ora, o episódio em pauta fornece, ainda, elementos valiosos para a compreensão dos sutis mecanismos de ação desse poder imanente e produtivo que visa encarregar-se da vida, otimizando-a. Como lembra Pelbart (2007, p. 58), referindo-se também a uma das características do exercício do poder na passagem de uma sociedade disciplinar para o que Deleuze chamou de sociedade de controle,

[...] já mal sabemos onde está o poder e onde estamos nós. O que ele nos dita e o que nós dele queremos. Nós próprios nos encarregamos de administrar nosso controle, e o próprio desejo já se vê inteiramente capturado. Nunca o poder chegou tão longe e tão fundo no cerne da subjetividade e da própria vida, como nessa modalidade contemporânea do biopoder.

No que diz respeito à discussão sobre o que vinha a ser saúde, grande parte dos discursos dos participantes relacionavam-na estritamente ao campo biológico e a tematizavam pelos perigos de se adquirir doenças. Na segunda oficina, a discussão sobre o tema o que é saúde? se deu a partir de uma atividade em que solicitei de cada participante que escolhesse, dentre dezenas de fotografias dispostas na sala, uma ou duas imagens relacionadas ao assunto. Mediante a apresentação e discussão das primeiras fotografias escolhidas, os sentidos conferidos ao que seria saúde remetiam a uma série de hábitos considerados pelos participantes como não saudáveis, principalmente no tocante à alimentação e aos cuidados com o corpo.

Pesquisador: Agora, a ideia é que, de um por um, é... cada um apresente a sua foto escolhida e tudo mais, e diga porque que escolheu essa foto e por que acha que essa foto tem a ver com saúde, ta certo? Pra gente começar a discutir...

(Mariana e Renata, ao mesmo tempo, pedem pra começar. Mariana faz sinal de que cede a vez para que Renata comece).

Renata: Esse menino comendo (exibe para o grupo a foto de uma criança comendo)... Assim, eu escolhi porque hoje em dia muitas crianças e jovens comem coisas que não deveriam comer exageradamente. Futuramente ela pode ter um caso muito sério de saúde.

Professor Ivan: Em relação a essa questão aí, a questão dos alimentos, realmente é um ponto que a gente tem que ter muito cuidado! Então assim, tudo que você exagerar futuramente cê vai colher principalmente algo ruim. Então, eu achei interessante a escolha dela por conta disso, do perigo dos alimentos.

Mariana: Até antigamente, nos interiores, iam fazer aquelas pesquisas, né? Aí o maior nível era de... como é o nome, meu Deus? Desnutrição. E hoje em dia não, até no interior, no lugar mais precário, é obesidade também.

-Professor Ivan: É um problema de saúde pública, né, hoje em dia, a obesidade. Muitos casos mesmo. E até assim, saúde é você tá com o organis-

Educação \& Realidade, Porto Alegre, v. 38, n. 1, p. 361-381, jan./mar. 2013.

Disponível em: <http://www.ufrgs.br/edu_realidade> 
mo legal, ou seja, o corpo em forma. E até assim, com o corpo legal, a aparência fica legal também, ajuda nos relacionamentos, né, que os jovens procuram (risos). Cuidar do corpo é sempre bom em todos os sentidos, valoriza a pessoa.

Pedro: Malhar, fazer esporte. Buscar uma vida mais equilibrada.

Camila: Evitar os excessos, né?

Professor Ivan: Exatamente. Aqui na escola a gente da biologia, da educação física procura estimular a pessoa a se cuidar, a estar em dia com o corpo, informar como ficar em forma, consumir coisas boas. Isso às vezes é chato, mas é totalmente saudável.

Camila: Aí mas às vezes é tão difícil!

(o grupo ri)

Professor Ivan: Difícil é! Mas pra ficar saudável tem que fazer sacrifício mesmo!

Laura: E eu acho assim, a saúde é uma questão das escolhas de cada um. Quanto mais informações você tem sobre o que é certo e o que é errado, mais você vai poder escolher o que é melhor pra saúde. Por isso é sempre bom ter a informação... tá antenado mesmo... dicas de saúde, né? Internet, jornal, revista, palestra, tudo isso ajuda que só!

Professor Ivan: E olha só. A educação prepara para o mercado de trabalho, né verdade? E a pessoa que se cuida fica até mais produtiva, fica até mais encaixada no mercado de trabalho. Como é que vai se dar bem num mundo tão competitivo como o de hoje se não escolher uma vida mais saudáveis, pra buscar um equilíbrio, digamos assim? (Barros, 2010, p. 87).

A partir desse episódio, pode-se pensar como a noção de saúde que balizava aqueles enunciados parecia ser a de um funcionamento regular e a de um cuidado de si visando à perfectibilidade do corpo. Os participantes também apontavam como questões-chave para a saúde a aquisição de informações sobre hábitos saudáveis e o discernimento individual para fazer escolhas nesse caminho.

Portanto, cabe trazer à baila algo já assinalado por Foucault (1979, p. 80): “o corpo é uma realidade biopolítica”. A propósito, escreve Pelbart (2007, p. 60),

[...] o foco do sujeito se deslocou da intimidade psíquica para o próprio corpo. Hoje, o eu é o corpo. A subjetividade foi reduzida ao corpo. A sua aparência, a sua imagem, a sua performance, a sua saúde, a sua longevidade [...]. Agora cada um de nós se submete voluntariamente a uma espécie de ascese, seguindo ora um preceito científico, ora um preceito estético. Por um lado trata-se de adequar o corpo às normas científicas da saúde: longevidade, equilíbrio. Por outro, trata-se de adequar o corpo às normas da cultura do espetáculo, conforme o modelo da celebridade. Essa obsessão pela perfectibilidade física, com as infinitas possibilidades de transformação anunciadas pelas próteses genéticas, químicas, eletrônicas ou mecânicas. [...] O fato é que nós abraçamos voluntariamente essa tirania da corporeidade perfeita, em nome de um gozo sensorial, cuja imediaticidade torna ainda mais surpreendente 
o seu custo em sofrimento. A bioascese é um cuidado de si, mas diferentemente dos antigos, cujo cuidado de si visava a bela vida, e que Foucault até chamava de estética da existência, o nosso cuidado de si visa o corpo, sua longevidade.

Em tempos neoliberais, esses processos ganham dimensões ainda maiores. Em Nascimento da Biopolítica, Foucault (2008b) aborda o neoliberalismo como uma prática de maximização da governamentalidade. Essa maximização ocorre da seguinte forma: o governo torna-se mais sutil e eficaz para ser mais econômico, de maneira que "para governar mais, é preciso governar menos” (Veiga-Neto, 2000, p. 184). Segundo Foucault, uma das táticas dessa governamentalidade neoliberal consiste numa política de subjetivação que amplifica, em seu benefício, a sensação de liberdade individual.

Alguns efeitos disso na educação são factíveis: o discurso de maximização da liberdade individual produz a sensação de que cada um é plenamente livre para fazer suas escolhas, coincidindo com a exacerbação do individualismo e da competição entre os indivíduos (Veiga-Neto, 2000). Tomando exatamente a questão da liberdade como eixo problematizador da relação entre governamentalidade e educação, Aquino e Ribeiro (2009) pontuam que a crescente convocação dos sujeitos ao exercício de uma liberdade intimizada e autorregulatória constitui uma das mais consistentes estratégias de governamentalização na atualidade, pois faz espraiar as modulações normativas por toda parte. Assim, perguntando-se sobre os objetivos da escolarização na e para a lógica neoliberal, Veiga-Neto (2000, p. 198) responde: “criar/moldar o sujeitocliente" nas suas escolhas de consumo.

Nesse sentido, o consumo de bens materiais e imateriais parece cada vez mais figurar como uma espécie de passaporte para a saúde. Tornou-se comum se referir à saúde como um atributo de responsabilidade estritamente individual, derivado do exercício da liberdade de escolha de cada um, a ser qualificado por um acúmulo de informações e prescrições a respeito. Logo, a equação parece ser: quanto mais consumo [ainda que de bens como informações], mais saúde! E, sob a lógica neoliberal, aí entrariam a escola e as práticas de saúde que nela têm lugar: treinar o sujeito a fazer escolhas produtivas e saudáveis.

Nesse contexto, cada vez mais se propaga um ideal de perfeição: uma perfeita saúde, uma perfeita alimentação, um perfeito corpo, um perfeito desempenho, etc. Ante um modelo praticamente inalcançável de saúde, as informações e as dicas sobre hábitos saudáveis soam como promessas para se lograr essa perfectibilidade idealizada. Abre-se, por conseguinte, espaços para novas ofertas de mercado: superespecialidades acadêmicas, manuais de autoajuda, revistas de saúde, suplementos alimentares, programas de televisão, restaurantes especializados, novas terapias, novos treinamentos e tratamentos estéticos, para todos os gêneros, todas as idades e todas as raças. 
Já no tocante ao tema saúde mental, que, em uma das oficinas, foi discutido com base na produção de cartazes por dois subgrupos, também foi marcante a maneira como os participantes significavam situações cotidianas que lhes pareciam relacionadas à doença mental:

(Renata termina de apresentar o cartaz do primeiro grupo. Os outros três participantes do grupo, Carla, Lia e Pedro, entreolham-se e Carla pede permissão para comentar uma foto de uma artista presente no cartaz) Carla: Eu queria dizer que aqui no caso da Amy Winehouse. A gente até discutiu isso em sala um dia com o professor. Ela foi assim tipo se maltratando, tipo que criando uma situação onde ela tinha crise, começou a ter distúrbios, começou a ter umas crises. Pronto, tipo, no show dela, ela vai bêbada, desmaia no palco, depois ela vai atrás dos fotógrafos bater (ri), bate neles, raspa cabelo e assim vai.

Pesquisador: Mas por que vocês lembraram dessa cantora pra colocar no cartaz?

Carla: Sei lá, porque ela é muito estranha, não tem o juízo certo. Ela se maltrata, ela bebe, ela fuma, ela usa drogas...toda perturbada.

Camila: E também o consumo das drogas, né, no caso dela, é o contrário da saúde mental.

Pesquisador: Então saúde mental significa não usar drogas? Quem usa essas coisas necessariamente não tem saúde mental?

Camila: Não é quem não tenha, mas vamos supor, não tem $100 \%$, total, é diferente do padrão, assim.

Carla: Porque isso das drogas também vai desgastar não só o corpo, mas também a mente. A gente aqui na escola vê muito isso (Barros, 2010, p. 99).

Portanto, os episódios interativos referentes aos temas o que seria saúde? e saúde mental permitem que, aqui, estabeleçam-se discussões sobre alguns processos contemporâneos de inclusão-exclusão social, os quais estão diretamente ligados ao tema da biopolítica (Gadelha, 2009). Na lógica da governamentalidade neoliberal, conceber saúde como um funcionamento regular e equilibrado do ponto de vista físicopsico-social, além de legitimar sua padronização, pode produzir efeitos que reforçam estratégias de controle e de exclusão de tudo considerado desassossego, fora do normal, perigoso ou improdutivo. O tema saúde mental entre aqueles atores escolares pareceu agenciar discursos legitimadores de padrões identitários, que, por sua vez, vão ao encontro da patologização e estigmatização dos que diferem das normais sociais de conduta.

Já o tema drogas, discutido na quinta e na sétima oficina, veio a lume mediante uma atividade de perguntas e respostas elaborada por duas jovens, Lia e Renata:

(Mariana pega a caixa com as perguntas, retira um papel com uma pergunta elaborada por Lia e Renata. Lê em voz alta a pergunta)

Mariana: "Marta tem 16 anos e foi convidada para uma festa de casamento. Tinha bebida na festa. Ela nunca havia bebido muito, mas, como estava quente, tomou uns quatro ou cinco deles. A frase 'evite o primeiro gole' serve para todos ou apenas para aqueles que são viciados, que estão em 
faze de tratamento?".

Pesquisador: O que vocês acham, gente, na frase "evite o primeiro gole é pra todos ou só pra quem já ta em tratamento?”

Mariana: Rapaz, eu acho que é pra todos. Porque, tipo assim, se você não conhece é melhor você não conhecer pra depois você não ter vontade de repetir, né. Aí é melhor prevenir do que remediar. Num é verdade? Pronto, falei.

[...]

Pesquisador: Mas toda pessoa que toma o primeiro gole se torna dependente?

(Lia, Mariana e Renata respondem ao mesmo tempo que não)

Mariana: Não, mas é melhor prevenir.

Renata: Vai que vicia.

Mariana: É, você não sabe, né.

Lia: Nem tanto viciar, mas fica tomando, aí vai que aumenta... a vontade. É melhor evitar

Laura: Assim, eu acho que quando a pessoa quer usar droga, ela sabe as consequências, ela sabe, usa porque ela quer. Porque a mídia fala, o colégio fala, mas a pessoa, num sei, ela tem uma ideia dela formada que pra ela ali é aquilo e pode falar o que você quiser, dizer o que quiser que a pessoa vai... Então, eu acho que a pessoa vai porque quer, porque informação tem aí, você pode ir na internet e procurar, você pode ir num posto de saúde falar com assistente social, você pode ir na televisão, colégio, a informação ta aí, a informação ta aí, agora basta se você querer aceitar (Brasil, 2010, p. 116).

Nesse episódio, assim como nas discussões ocasionadas pela oficina que tratou particularmente do tema drogas, ficou evidente a força dos discursos do risco e da prevenção entre os próprios jovens. Uma questão curiosa sugere como os jovens se apropriavam do discurso da prevenção às drogas: as alternativas de combate a esse uso que apareciam nos enunciados dos jovens passavam por campanhas de regulação das condutas da população, como ficava explícito em sentenças como Evite o primeiro gole e $E$ melhor prevenir do que remediar.

Assim sendo, há conexão entre discurso da prevenção e da normalização da conduta juvenil, presente na própria fala dos jovens em relação ao combate às drogas, e o modo de abordar o tema "drogas" no espaço escolar?

Mülller, Paul e Santos (2008, p. 610) ressaltam duas das principais maneiras pelas quais o uso e o abuso de drogas historicamente têm sido abordados no contexto escolar:

[...] a primeira que estimula a proibição, pela diminuição da oferta, com informações que se caracterizam pelo apelo moral e produção de medos, persuadindo as pessoas à abstinência; a segunda é a redução de danos, com propostas como: oferecimento de alternativas, educação para a saúde e modificações das condições de ensino.

Para Moreira, Silveira e Andreoli (2006), o discurso proibicionista ${ }^{2}$ é o que predomina em grande parte das práticas realizadas no âmbito 
escolar. Com efeito, a emergência de enunciados como Evite o primeiro gole! e É melhor prevenir do que remediar! são indícios de como aquele discurso orientava os posicionamentos dos participantes do grupo de discussão frente a esse tema.

Além disso, nas observações que realizei no lócus da pesquisa, conheci iniciativas desenvolvidas por alguns profissionais da escola, principalmente um projeto de um dos professores. Cartazes com informações sobre os danos causados pelo álcool e pelo tabaco, distribuição de panfletos, solicitação de trabalhos junto dos estudantes sobre os malefícios de substâncias psicoativas e realização de seminários em sala enfocando essa temática foram exemplos de ações com as quais pude entrar em contato na escola.

A seguir, um trecho do diário de campo que registrou momentos do processo de elaboração de uma campanha de prevenção ao uso de drogas na escola, aproveitando as comemorações do dia 7 de Setembro:

\begin{abstract}
Antes do início do recreio, aproveitei para ficar na sala dos professores conversando com quatro professores e com uma coordenadora da escola. Três dos quatro professores participavam mais da conversa, enquanto corrigiam trabalhos dos alunos. O outro colocava-se apenas eventualmente. Ele parecia bastante concentrado imprimindo e recortando panfletos. Aquela tarefa gerou curiosidade não só em mim, como também nos demais presentes na sala. O professor nos contou que estava preparando um material que serviria para uma campanha de prevenção ao uso de drogas que ele estava promovendo junto aos estudantes. Segundo ele, a campanha envolveria alguns esclarecimentos em sala de aula relativos às drogas e distribuição de panfletos. Sua intenção era que a campanha perdurasse até os dias que antecediam o 7 de Setembro. O professor me mostrou o texto do panfleto a ser distribuído aos estudantes: "Conquiste sua independência em relação às drogas". Segundo o docente, o texto fazia um trocadilho com o dia da independência e preconizava a independência química e social por parte dos estudantes (Diário de Campo, 04 set. 2009).
\end{abstract}

Para sustentar o seu valor pragmático de orientação aos estudantes na escola, era necessário que o enunciado Conquiste sua independência em relação às drogas estivesse situado num interdiscurso. Entre esses discursos, estavam aqueles apropriados pelos estudantes do grupo de discussão: Diga Não às Drogas! e Evite o primeiro gole!. O panfleto em questão circulou indistintamente na escola. Assim, pragmaticamente, é plausível supor que o enunciado acima só fez sentido como carro-chefe da campanha porque pareceu presumir que alguns dos jovens da escola eram, sim, dependentes químicos, enquanto os outros destinatários, no mínimo, foram posicionados como jovens em risco de se tornarem dependentes um dia. 
Por seu turno, nas discussões sobre sexualidade, ocorridas principalmente na sexta oficina, discutimos, entre outras questões, sobre as ações nesse âmbito existentes na escola. Foi possível identificar, no tocante a isso, posições enunciativas que traziam à tona enunciados que dissociavam sexo e prazer, bem como recomendações de caráter preventivo que caracterizavam grande parte das ações de educação sexual:

Pesquisador: E, no caso, vocês já... disseram que já assistiram varias coisas nesse sentido, palestras, aulas, seminários. Quando se fala em sexualidade esses trabalhos enfocam o que?

Mariana: Como se prevenir...(é interrompida por Camila)

Camila: Prevenção de doenças

Mariana: Fala das possibilidades da pessoa que já engravidou, fala assim..

$[\ldots]$

Pesquisador: E por que que quando se fala em sexualidade pra adolescentes, pra jovens, se fala desse jeito, se fala dessas coisas?

Camila: Eles falam pra gente dessa maneira já dizendo: "Olha, eu tô dizendo pra vocês que isso [sexo] é errado, eu to dizendo pra você não fazer isso".

Renata: Eu acho que eles falam porque é um dos fatores mais comuns, assim, gravidez, DST.

[...]

Pedro: Eu acho que se fala mais... se fala mais os pontos pior, tipo, o que acontece quando a mulher engravida na adolescência, as DSTs são as doenças... Acho que o pessoal só fala só da parte ruim, é, tipo, como se fosse pra botar medo, pra pessoa não fazer isso. Por causa que se ela for falar: "Ah, a mulher, é muito bom ser mãe", esse tipo de coisa é um incentivo e as pessoas, os pais, nem todo mundo quer que a filha engravide, por isso que fala mais os pontos ruins, pra evitar a pessoa fazendo isso (Barros, 2010, p. 127).

De acordo com Gadelha (2009), a questão da norma é um ponto fulcral para aproximar biopolítica e educação a partir da obra de Foucault. Isso por que:

[...] o elemento que vai circular entre o disciplinar e o regulamentador, que vai se aplicar, da mesma forma, ao corpo e à população, que permite a um só tempo controlar a ordem disciplinar do corpo e os acontecimentos aleatórios de uma multiplicidade biológica, esse elemento que circula entre um e outro é a "norma". A norma é o que pode tanto se aplicar a um corpo quanto a uma população que se quer regulamentar (Foucault, 1999, p. 302).

Nesse sentido, os signos do risco e da prevenção, ao virem à tona principalmente nas discussões sobre drogas e sexualidade, parecem aspectos que ilustram bem alguns mecanismos pelos quais as práticas discursivas em torno da saúde agenciavam cruzamentos entre disciplinamento dos indivíduos e processos biopolíticos de normalização social da vida do corpo-espécie da população juvenil. Por isso, tais signos podem ser considerados aqui como importantes indicadores das es- 
tratégias governamentalizadoras em ação na escola. Na interface entre norma disciplinadora e norma regulamentadora, essas estratégias não se restringem a excluir os diferentes, a vigiar e punir anormalidades, a coagir os corpos pelo disciplinamento, visto que também buscam incluir diferenças, orientar as condutas dos indivíduos sobre si mesmos, angariar a adesão voluntária de todos em nome de ideias consensuais, sob um viés preventivo que antevê riscos e se antecipa às condutas.

Ao longo das discussões do grupo de discussão, foi possível identificar também resistências a esse processo de normalização. Nesse último episódio, os jovens se colocaram diferencialmente frente aos pontos de vistas já assumidos, denunciando contradições do discurso da educação em saúde. Em alguns trechos, Mariana, Pedro e Camila põem em parêntese o discurso social vigente sobre sexualidade, que tantas vezes atravessou as falas dos participantes, posicionando-se criticamente diante do caráter repetitivo e unilateral que as atividades educativas teriam. Aliás, no final do episódio, um diferencial no processo enunciativo foi provocado por Pedro, que interpela uma certa pedagogia do medo muitas vezes utilizada com o intuito de instigar a prevenção de doenças. Dessa forma, a voz de Pedro insurgia contra o enfoque negativo dado ao tema da sexualidade junto aos jovens e muitas vezes incorporado pelos próprios jovens ao falarem deste tema, como observado em outros episódios.

\title{
Considerações Finais
}

Os autores que tratam das práticas de saúde no campo educacional e os episódios interativos trazidos ao longo do texto fornecem elementos plausíveis para a discussão de como os agenciamentos produzidos por aquelas práticas sugerem complexas alianças entre mecanismos disciplinares e biopolíticos em instituições como a escola, com vistas à regulação da vida dos segmentos infantojuvenis. Foi possível perceber que tais alianças se estabelecem da seguinte maneira:

\begin{abstract}
Se os regimes disciplinares privilegiam a condição de fixidez da norma, esquadrinhando os indivíduos de acordo com os nichos normal/anormal, a investida governamentalizadora, por sua vez, aciona o efeito modular da norma, mapeando e recolhendo a multiplicidade de ações emergentes em determinado plano (sempre contingencial) de possibilidades de condutas. (Aquino; Ribeiro, 2009, p. 63).
\end{abstract}

Em particular, os episódios do corpus da pesquisa, como aqueles que apontam a saúde como funcionamento regular e aqueles que articulam sexualidade e risco, ilustram práticas discursivas que parecem envidar esforços na direção do delineamento de uma juventude asséptica. Assim, os discursos sobre temas de alguma forma ligados à saúde (o que seria saúde, saúde mental, drogas e sexualidade, por exemplo) ad- 
quiriam, por vezes, conotação moralizadora pelos próprios participantes no espaço escolar, tratando da formação de indivíduos responsáveis, que se autopreservam, autovigiam-se e que introjetam as retóricas da perfeita saúde e do risco, de modo a orientarem suas escolhas para um estilo de vida produtivo.

Mas, com essas colocações, este texto não pretende endossar previsões pessimistas no que concerne às implicações políticas da educação na contemporaneidade. Pelo contrário, acredito que as possibilidades de agenciamento de processos de subjetivação pela educação ainda estão em aberto, mesmo por que:

[...] com os olhos postos nos interesses da lógica neoliberal, qual outra instituição poderia, a curto prazo, substituir a maquinaria escolar para montar, tão ampla e rapidamente, um tal sujeito-cliente? Por outro lado, com os olhos postos numa vontade de resistência, qual outra instituição poderia ser mobilizada - também tão ampla e rapidamente - para tentar aumentar as fraturas numa lógica contra a qual muitos querem lutar? (Veiga-Neto, 2000, p. 214).

De acordo com o ponto de vista foucaultiano, a resistência ao biopoder se encontra em seu próprio objeto: a vida. Logo, há que se investir nas possibilidades de que a educação e a escola fomentem cada vez mais resistências à constituição de identidades e de maneiras de viver, agir, sentir e pensar sujeitadas, regulamentadas e controladas. A partir de um viés ético-estético, a efetivação de tais possibilidades de resistência passa, por exemplo, pela elaboração de dispositivos que retomem o corpo no seu poder de afetação, que problematizem as expressões da governamentalidade neoliberal e que colaborem com a invenção de maneiras singulares de se relacionar consigo e com o outro.

Embora na pesquisa-intervenção não tenhamos como controlar as reverberações das narrativas de si e do Outro produzidas no contexto do grupo de discussão, podemos supor que novos posicionamentos só podem ser construídos "quando os sujeitos vivem a possibilidade de narrá-los, de expressá-los sem tantas censuras" (Menezes; Arcoverde; Libardi, 2008, p. 221). Dessa forma, a própria pesquisa-intervenção pode se configurar como espaço de resistência e desterritorialização, o que pode ser ilustrado no momento em que os jovens, em determinadas ocasiões, produziram questionamentos em relação às práticas de saúde tradicionalmente direcionada ao segmento social de que fazem parte. Tais situações sinalizam que a própria vida resiste no espaço escolar aos mecanismos de disciplinamento, de governamento e de regulação biopolítica, deixando, portanto, em aberto possibilidades de singularização.

Assim sendo, avaliamos que o grupo de discussão foi útil para a criação de dispositivos de análise coletiva naquela escola, compatibilizando o aprofundamento de informações com a problematização do

Educação \& Realidade, Porto Alegre, v. 38, n. 1, p. 361-381, jan./mar. 2013.

Disponível em: <http://www.ufrgs.br/edu_realidade> 
cotidiano e possibilitando, consequentemente, reposicionamentos dos participantes frente aos temas debatidos. A propósito, as discussões sobre a saúde oportunizadas pela pesquisa-intervenção contribuíram para que questões indiscutíveis sobre saúde viessem à tona naquele contexto. Igualmente, serviu para problematizar o que era concebido pelos adolescentes como algo natural, não só relativo aos sentidos sobre os temas, mas inclusive com relação às próprias ações educativas em saúde que lhes eram direcionadas, dentro e fora da escola.

Recebido em 12 de julho de 2011 Aprovado em 01 de junho de 2012

\section{Notas}

1 Todos os nomes dados aos participantes neste texto são fictícios.

2 Segundo Muller, Paul e Santos (2008), o que caracteriza esse discurso é a ênfase nos danos causados pelo uso de drogas e nas proibições relacionadas a esse uso.

\section{Referências}

ABERASTURY, Arminda. A Adolescência. Porto Alegre: Artes Médicas, 1980.

ABRAMO, Helena. Condição Juvenil no Brasil Contemporâneo. In: ABRAMO, Helena; BRANCO, Pedro Paulo (Org.). Retratos da Juventude Brasileira: análises de uma pesquisa nacional. São Paulo: Perseu Abramo, 2008. P. 37-72.

AQUINO, Julio; RIBEIRO, Cyntia. Processo de Governamentalização e a Atualidade Educacional: a liberdade como eixo problematizador. Educação \& Realidade, Porto Alegre, Universidade Federal do Rio Grande do Sul, v. 34, n. 2, p. 57-72, maio/ago. 2009.

BARROS, João Paulo Pereira. Interações em um Grupo de Discussão sobre Saúde: estudo de seu caráter mediador na constituição subjetiva dos participantes. 2010. 186f. Dissertação (Mestrado em Psicologia) - Programa de Pós-Graduação em Psicologia, Universidade Federal do Ceará (UFC), Fortaleza, 2010.

BRASIL. Lei no 9.394, de 20 de dezembro de 1996. Estabelece as diretrizes e bases da educação nacional. Diário Oficial [da] República Federativa do Brasil, Brasília, DF, 23 dez. 1996.

BRASIL. Secretaria da Educação Fundamental. Parâmetros Curriculares Nacionais: introdução aos Parâmetros Curriculares Nacionais. Brasília: MEC/ SEF, 1997.

FIGUEIREDO, Túlio; MACHADO, Vera; ABREU, Mirian. A Saúde na Escola: um breve resgate histórico. Revista Ciência e Saúde Coletiva, Rio de Janeiro, Associação Brasileira de Pós-Graduação em Saúde Coletiva/ABRASCO, v. 15, n. 2, 2010, p. 397-402, mar. 2010.

FOUCAULT, Michael. Microfísica do Poder. Rio de Janeiro: Graal, 1979.

FOUCAULT, Michael. A Ordem do Discurso. São Paulo: Loyola, 1996.

FOUCAULT, Michael. Em Defesa da Sociedade. São Paulo: Martins Fontes, 1999. FOUCAULT, Michael. Vigiar e Punir: história de violência nas prisões. Petrópolis: Vozes, 2005. 
FOUCAULT, Michael. Segurança, Território, População. São Paulo: Martins Fontes, 2008a.

FOUCAULT, Michael. Nascimento da Biopolítica. São Paulo: Martins Fontes, 2008b.

GADELHA, Sylvio. Biopolítica, Governamentalidade e Educação: introdução e conexões a partir de Michel Foucault. Belo Horizonte: Autêntica, 2009.

GUATTARI, Félix; ROLNIK, Suely. Micropolítica: cartografias do desejo. Petrópolis: Vozes, 2005

LIMA, Gerson. Saúde Escolar e Educação. São Paulo: Cortez, 1985.

MENEZES, Jaileila Araújo; ARCOVERDE, Lilian Rocha; LIBARDI, Suzana Santos. A Pesquisa-Intervenção com Adolescentes: oficina como contexto narrativo sobre igualdade e diferença. In: CASTRO, Lucia Rebello de; BESSET, Vera Lopes (Org.). Pesquisa-Intervenção na Infância e Juventude. Rio de Janeiro: Trarepa/ FAPERJ, 2008. P. 205-223.

MOREIRA, Fernanda; SILVEIRA, Dartiu; ANDREOLI, Sérgio. Redução de Danos do Uso Indevido de Drogas no Contexto da Escola Promotora de Saúde. Revista Ciência e Saúde Coletiva, Rio de Janeiro, Associação Brasileira de Pós-Graduação em Saúde Coletiva/ABRASCO, v. 11, n. 3, p. 807-816, jul./set. 2006.

MÜLLER, Ana; PAUL, Cátia; SANTOS, Nair. Prevenção às Drogas nas Escolas: uma experiência pensada a partir dos modelos de atenção em saúde. Estudos de Psicologia (Campinas), Programa de Pós-Graduação em Psicologia do Centro de Ciências da Vida da Pontifícia Universidade Católica de Campinas, v. 25, n. 4, p. 607-616, out./dez. 2008.

PELBART, Peter. Biopolítica. Sala Preta, São Paulo, USP, v. 7, n. 1, p. 57-66, 2007

SCHALL, Virgínia; STRUCHINER, Miriam. Educação em Saúde: novas perspectivas. Cadernos de Saúde Pública, Rio de Janeiro, Escola Nacional de Saúde Pública Sergio Arouca, Fundação Oswaldo Cruz, v. 15, n. 2, p. 04-05, 1999.

STEPHANOU, Maria. Formar o Cidadão Física e Moralmente: médicos, mestres e crianças na escola elementar. Educação, Subjetividade e Poder, Porto Alegre, v. 3, n. 3, p. 59-66, jan./jun. 1996.

VEIGA-NETO, Alfredo. Educação e Governamentalidade Neoliberal: novos dispositivos, novas subjetivações. In: PORTOCARRERO, Vera; CASTELO BRANCO, Guilherme. Retratos de Foucault. Rio de Janeiro: Nau Editora, 2000. P. 179-217.

João Paulo Pereira Barros é psicólogo, mestre em Psicologia e doutorando em Educação Brasileira pela Universidade Federal do Ceará (UFC) em Fortaleza, Ceará. Especialista em Saúde Mental pela Universidade Estadual do Ceará (UECE), em Fortaleza, Ceará. Professor Assistente do Curso de Psicologia da Universidade Federal do Piauí (UFPI), na Área de Psicologia e Saúde Coletiva - Campus Parnaíba, Piauí. País: Brasil. Teresina/ Piauí.

E-mail:jppbarros@yahoo.com.br 